\title{
Comparison Between the Amount of Penicillin G Residue in Raw and Pasteurized Milk in Iran
}

\author{
Zohre Ghanavi ${ }^{1,{ }^{*}}$, Saeed Mollayi ${ }^{2,{ }^{*}}$, Zahra Eslami ${ }^{3}$ \\ ${ }^{1}$ Institute of Standard and Industrial Research of Iran, Tehran, IR Iran \\ 2 Young Researchers and Elites Club, North Tehran Branch, Islamic Azad University, Tehran, IR Iran
}

${ }^{*}$ Corresponding authors: Saeed Mollayi, Young Researches and Elites Club, North Tehran Branch, Islamic Azad University, Tehran, IR Iran, Tel: +98-2122431598, Fax: +98-2122431598, E-mail: Smollayi@ymail.com; Zohre Ghanavi, Institute of Standard and Industrial Research of Iran, Tehran, IR Iran. Tel: +98-9125817046, Fax: +98-2122431598, E-mail: Z_ghanavi@ yahoo.com.

Received: Jun 09, 2013; Revised: Jun 29, 2013; Accepted: July 14, 2013

\begin{abstract}
Background: There is a worldwide concern about the life quality, in this way, one of the most important requirements is safe and nutritious foodconsumption. The administration of antibiotics to cattle in order to treat several infectious diseases has contributed to the contamination of industrialized dairy farms.

Objectives: Milk antibiotic contamination is an important problem worldwide, and the quality control of milk samples is essential. Therefore, the aim of this study was to monitor antibiotic contamination in milk samples.

Materials and Methods: Samples were collected from six different farms and milk factories in Iran, and were tested by beta-star and cylinder-plate methods.

Results: Among 992 raw milksamples, 236 positive samples, 9 suspected and 747 negative samples in respond to beta-star testand among 236 samples, which had positive responses to beta-star test, 28 positive, 0 suspected and 208 negative results of cylinder-plate test were gained. Among 652 pasteurized milk samples, 67 positive, 9 suspected and 576 negative beta-star test results and among 67 samples which had positive responses to beta-star test, 1 positive, 0 suspected and 66 negative results to cylinder-plate test were achieved.

Conclusions: The results revealed that cylinder-plate method accompanied with beta-star test can be considered as an appropriate sensitive and selective method for the milk and dairy products quality control. According to the results, it look as if the process of pasteurization reduces the amount of penicillin $\mathrm{G}$ in milk samples considerably.
\end{abstract}

Keywords: Penicillin G; Milk; Antibiotics; Pasteurization

\section{Background}

The importance of milk and its related products in human diet has been thoroughly realized since early times. Milk is one of the most appropriate and moderate foods including various types of proteins, lipids, minerals (calcium, phosphate and potassium), vitamins (D, A, B2, B12), lactose and the entire amino acids required for the maintenance, growth and development of the body tissues (1). Checking the milk quality and making assurance of its healthiness is of great importance. In order to improve the milk quality and healthiness, it should be free of every physical, biological and chemical contaminations. For instance, different kinds of antibiotics, most typically the Benzylpenicillin (2), which can basically cause numerous problems to the dairy industry (3-5).

Several studies were conducted to determine antibiotic availability in milk and milk products in different countries. Monitoring of the raw and pasteurized milk sam- ples in the United States of Canada and the UK from 1955 and 1959 , shown that more than $6.11 \%$ of the samples were contaminated with penicillin (6). A study performed in 1958 and 1959 in South Africa showed that 3\% of 1200 investigated samples, were contaminated with penicillin (6). A survey in Pennsylvania published in 1959 revealed that $77 \%$ of the dairy farmers have not discard treated milk for a 72-hour period (7). The State of Pennsylvania now has a law insisting on testing all milk products once a month for antibiotic residues (8). Afnan and Kashani indicated that among 402 raw and 432 pasteurized milk samples, $22.5 \%$ of raw milk samples and $5.2 \%$ of pasteurized ones were contaminated (9). In another study, Karim and Nawab indicated that over 52\% of the milk samples were contaminated by drug residues (10).

If the contaminated Milk with antibiotic residues is used, it will contaminate other dairy products. If the milk is dried, evaporated, or made into ice cream, the antibiot-

Implication for health policy/practice/research/medical education:

Using different kinds of antibiotics in milk, especially penicillin G, can cause numerous difficulties such as Urticaria, Anaphylactic shock and even death in humans. Therefore, based on aims of standard institute of Iran (quality of goods, support of consumers, helping to improve production methods), we tried to analysis penicillin $\mathrm{G}$ by using beta-star test and Cylinder-plate method in raw and Pasteurized milk.

Copyright @ 2013, Ahvaz Jundishapur University of Medical Sciences; Licensee Kowsar Ltd. This is an Open Access article distributed under the terms of the Creative Commons Attribution License (http://creativecommons.org/licenses/by/3.0), which permits unrestricted use, distribution, and reproduction in any medium, provided the original work is properly cited. 
ic concentrates in these processed products. Although no manufacturing problems resulted from the presence of antibiotics in the above-mentioned products, but either a consumption or utilization problems are present. On the other hand, the Food and Drug Administration could not detect any antibiotic in evaporated milk, ice cream, powdered milk, and butter samples tested in 1954 (11). Maicth and Ellickson (12) analyzed dried skim milk and whey for the presence of penicillin. They found 0.05- 0.1 unit Penicillin per $\mathrm{mL}$ of milk in whey which contained antibiotics. Penicillin-positive samples of dried skimmed milk contained between 0.5 and 2.5 units Penicillin per gram of product.

According to the literatures, the most efficient assay for determination of Penicillin in milk and dairy products are LC-MS/MS $(13,14)$, Fourier transform near infrared spectroscopy (15), enzyme immunoassay (16) and microbial assays $(17,18)$; amongst the microbial assays can demonstrate tiny changes which are not detectable by chemical methods (19). Besides, microbial assay is capable to determine the effectiveness of the antibiotic, which is an outstanding feature of this method. The "traditional" tests for antibiotics in milk, known as "microbial inhibitory" tests, involve incubating a susceptible organism in the presence of the milk sample. In the absence of any antibiotic, the organism grows and can be detected visually either by cloudiness of the agar growth medium or by a color change resulting from acid production.

In the presence of an antibiotic, or any other inhibitor, the organism fails to grow and a zone of inhibition or absence of a color change is observed. Such tests are exceptionally sensitive to ß-lactam antibiotics, though they can detect sulfonamides and other antimicrobial drugs. They are generally reliable and cost-effective but require long incubations before result observation. Several tests for antibiotic detection have been launched in the UK within the last 18 months. The beta-Star test including a specific ß-lactam receptor linked to gold particles. It is a 'dipstick' test that detects Penicillins and Cephalosporins within $5 \mathrm{~min}$, however, extending the incubation to 8 min makes the test more sensitive. The milk sample is added to a vial containing the reagents (25 test kit only: for a 100-test kit are added separately) and incubated, the dipstick is added and incubated. A red 'control' band appears on the dipstick with a red 'test' band of variable intensity and the latter is compared visually with the former. If the 'test' band is blunter than the 'control' band the result is positive; if the 'test' band is sharper, the result is negative (20-22).

Since dairy cows, as the main producers of the milk, are at the risk of infectious diseases particularly Mastitis, the need of antibiotic consumption is fundamental. Based on statistics and recent enquiries, mishandling of drugs to control Mastitis is the main source of the existence of drug residues in milk (23). It is highly noted that the drug residues concentration in milk must be lower than those mentioned in 1969 by FAO/WHO (24). The maximum residue limit for veterinary drugs (MRLVD) test has been modified several times and newly-emerging drugs have been continuously provided. Since milk and dairy products are considered as a healthy and comprehensive nutrient among folks, attempts in favor of the cited views are essential (24).

\section{Objectives}

Milk antibiotic contamination is an important global problem, thus qualitative and quantitative controls of milk samples are necessary. Consequently, the aim of this study was to monitor antibiotic contamination in milk samples using beta-star test and cylinder plate method.

\section{Materials and Methods}

\subsection{Samples and Reagents}

992 milk samples and three replications of each were collected from farms and milk industries in 2011. Seed Agar and Yeast Beef Agar were purchased from HIMEDIA, Sweden. Potassium dihydrogen phosphate and K2HPO4 were purchased from Merck Company, Germany. Penicillinase ( $\beta$-lactamase) and Penicillin G standard were provided by Sigma, USA. Micrococus loteus (ATCC 9341) was purchased from IAM, Japan.

\subsection{Preparation of Penicillin G Standard Solution}

$100 \mu \mathrm{g} . \mathrm{mL}^{-1}$ stock solution of standard Penicillin G was prepared by dissolving $100 \mu \mathrm{g}$ of the standard in $1 \mathrm{~mL}$ of phosphate buffer. Different concentrations of 0.2, 0.1, $0.05,0.025,0.0125,0.0067$ and $0.000625 \mu \mathrm{g} . \mathrm{mL}^{-1}$ were prepared by adding the corresponding amounts of healthy and sterile milk.

\subsection{Cylinder Plate Method}

In order to perform Cylinder plate test, M. loteus (ATCC 9341) was used. Microbial suspension was prepared as follow: adequate amount of tested microorganism was cultivated on an agar medium in a way that the entire surface of the agar was covered by the microorganism. Then the medium was hold at $32-35^{\circ} \mathrm{C}$ for $18-24 \mathrm{~h}$. Following, the microbial layer on the surface of the agar was transferred to seed agar and was hold at $32-35^{\circ} \mathrm{C}$ for $18-24$ h. Optimum inhibition is achieved when only $20 \%$ of the light with $650 \mathrm{~nm}$ length is passed from the suspension. Anti-bacterial activities of Penicillin G standard solutions and milk samples were investigated through cylinder plate method. Plates were kept at room temperature for 3 $\mathrm{h}$ and then at $30^{\circ} \mathrm{C}$ for $18 \mathrm{~h}$.

\subsection{Beta-star Test}

The commercially available beta-star test is a receptor assay for rapid detection of ß-lactam antibiotic residues 
Ghanavi Z et al.

in milk. The test is interpreted by visual comparison of a band with a reference band. Results are classified in to 4 categories; steps 2,3 and 4 are interpreted as positive. The control samples were prepared according to ISO18330/ IDF 188:2003. $0.2 \mathrm{~mL}$ of the sample was injected into the vials by the use of the automatic syringe and plastic micropipette. Vials were incubated at $47.5^{\circ} \mathrm{C}$ for $3 \mathrm{~min}$ and then one dipstick was dipped into every vial. Then, vials were again incubated at the same temperature for $2 \mathrm{~min}$.

\subsection{Statistical Analyses}

This experiment was carried out in a completely randomized design (CRD) with three replications. Data were analyzed statistically by the Statistical Package for Social Sciences (SPSS) 16.

\section{Results}

In order to screen the antibiotic contaminated sample, beta-star test was selected. Results of beta-star test are shown in Table 1 . As it is shown in Table 1, $23.8 \%$ of the raw milk samples and $10.2 \%$ of the pasteurized milk samples were estimated to have positive responses. However, beta-star test is responding to all beta lactam antibiotics, the type of antibiotic is not detectable by using this test.

Table 1. Results of the Bata-Star Test of Milk Samples with Three Replications Collected from Farms and Milk Industries in 2011

\begin{tabular}{llclc}
\hline & \multicolumn{2}{l}{ Raw Milk, No. (\%) } & \multicolumn{2}{l}{ Pasteurized Milk, No. (\%) } \\
\hline Positive & 236 & 23.8 & 67 & 10.2 \\
Suspected & 9 & 0.9 & 9 & 1.4 \\
Negative & 747 & 75.3 & 576 & 88.4 \\
Total & 992 & 100 & 652 & 100
\end{tabular}

Therefore, samples which had positive responses to beta-star test were tested by cylinder plate method and results are shown in Table 2. Results of Table 2 indicate that $11 \%$ of the raw milk samples and $1.5 \%$ of the pasteurized milk samples were contaminated by Penicillin G.

Table 2. Results of the Cylinder Plat Tests for Milk Samples with Three Replications collected from Farms and Milk Industries In 2011

\begin{tabular}{lllll}
\hline & \multicolumn{2}{l}{ Raw Milk, No. (\%) } & \multicolumn{2}{l}{ Pasteurized Milk, No. (\%) } \\
\hline Positive & 28 & 11 & 1 & 1.5 \\
Suspected & 0 & 0 & 0 & 0 \\
Negative & 208 & 89 & 66 & 98.5 \\
Total & 236 & 100 & 67 & 100
\end{tabular}

Anti-bacterial activity of each standard solution was evaluated by cylinder-plate method measuring the microbial inhibition zone. Results were used in order to draw the calibration curve. A graph of the standard inhibition zone values was drawn alongside the Penicillin $G$ concentrations in $\mu \mathrm{g} \cdot \mathrm{mL}^{-1}$. The amounts of Penicillin $\mathrm{G}$ residues are indicated in Table 3.

Table 3. Amount of Penicillin G in Milk Samples which were Collected from Farms and Milk Industries in 2011 by Cylinder Plat Method

\begin{tabular}{lllll}
\hline & Raw Milk & & \multicolumn{2}{c}{ Pasteurized Milk } \\
\hline Province & $\begin{array}{l}\text { Num- } \\
\text { ber of } \\
\text { Samples }\end{array}$ & $\begin{array}{l}\text { Average } \\
\text { concen- } \\
\text { tration } \\
\left(\mu \text { g.mL }^{\mathbf{1}}\right)\end{array}$ & $\begin{array}{l}\text { Num- } \\
\text { ber of } \\
\text { Samples }\end{array}$ & $\begin{array}{l}\text { Average } \\
\text { Concen- } \\
\text { tration } \\
\left(\mu \text { g.mL }^{-1}\right)\end{array}$ \\
\hline Zanjan & 42 & 0.5 & 11 & 0 \\
\hline Tehran & 43 & 2.2 & 10 & 0 \\
\hline Kerman & 40 & 1.74 & 15 & 0 \\
\hline Gilan & 30 & 0.67 & 10 & 0 \\
\hline Mashhad & 41 & 1.35 & 11 & 0.21 \\
\hline Gorgan & 40 & 0.55 & 10 & 0 \\
\hline Total & 236 & 1.2 & 67 & 0.04 \\
\hline
\end{tabular}

\section{Discussion}

In this study, $23.8 \%$ of raw milk samples s and $10.2 \%$ of pasteurized milk samples were shown the presence of beta lactam antibiotic residues in Iran, which has a very high prevalence for Iran. Table 1 compares the positive, negative, and suspected results of raw and pasteurized milk samples to beta-star test. As it is indicated, while about one fourth of raw milk samples had positive responses to this test, while only one tenth of the pasteurized samples showed positive results. This data demonstrates that pasteurizing milk samples results show more than two folds reduction of betalactam antibiotic levels in samples. Also, beta star kit could detect all kind of beta lactams in milk.

The result showed that the level of beta lactam antibiotic residues in milk were high in milk in Iran. This report is in accordance with other reports in other countries. In Iran, Movassagh and Karami. showed that $5 \%$ of cow raw milk was positive for antibiotics residues (25). Kaya and Filazi reported that in 204 raw milk samples, about $44 \%$ was positive for antibiotic residues (26). Khaskheli et al. (27) showed that of all samples $36.5 \%$ were contaminated by beta lactam antibiotic residues in cow raw milk in Pakistan. The prevalence of antimicrobial residues in preprocessed and processed cow milk in Trinidad were studied, and reported that $10.8 \%$ of all samples were positive (28). In a study by Shitandi of a total of 1109 milk samples collected from Kenya, 21\% was positive for antibiotic residues (29). Ceyhan and Bozkurt (30), in 200 raw milk samples, $5.5 \%$ was positive for antibiotic residues in Ankara region. In human, drug allergy is a well-established side-effect of the therapeutic usage of antibiotics, especially the betalactams.

Monitoring of beta-lactam residues of edible tissues and milk is important because of the hypersensitivity of some individuals to these antibiotics and also the emer- 
gence of antibiotic-resistant strains of bacteria. In addition to allergic reaction, there are some indications in the scientific literature suggesting that antibiotics can induce cancer and other non-cancerous health hazardous effects. Kosikowski (31) recently collected data on the national incidence of antibiotic residues in milk from January 1 to October 15, 1960--a period of testing and surveillance by dairy and regulatory officials. A survey in Pennsylvania published in 1959 revealed that $77 \%$ of the dairy farmers were not discarding treated milk for a 72hour. period (7). The presence of antibiotics in milk has been reported in Canada (32). Starter cultures were inhibited in milk from $7.3 \%$ of 344 herds sampled in spring of 1952 that $5.4 \%$ of 298 herds expressed similar degrees of inhibition in the summer of the same year. The presence of antibiotics in milk has been reported in Canada (32). Starter cultures were inhibited in milk from $7.3 \%$ of 344 herds sampled in spring of 1952 and $5.4 \%$ of 298 herds expressed similar degrees of inhibition in the summer of the same year.

Since beta-star method is responding to all beta lactam antibiotics, it would be better to select a method which is specific to Penicillin G. Though, cylinder plate method is a time-consuming, expensive and difficult test, compared with beta-star test. Therefore, it was necessary to screen all samples with beta-star test before performing cylinder plat test for samples which had positive response to beta-star test. Thus, cylinder method was utilized. On top of that, beta-star is a qualitative method which is only capable to reveal the presence of the beta lactam antibiotics and cannot measure the exact amount of contamination. On the other hand, cylinder plate is a quantitative technique to measures the amount of contamination that makes it a suitable method for determination of Penicillin $\mathrm{G}$ in milk samples. Table 2 shows the responses of raw and pasteurized milk samples to cylinder plate method. Around $11 \%$ of the raw samples showed positive responses to this method, while according to cylinder plate method only $1.5 \%$ of the pasteurized samples were contaminated to Penicillin G antibiotic, meaning that the process of pasteurization resulted in a about 8-times reduction of Penicillin G contamination within milk samples.

In comparison with the results of Table 1, the percentage of contaminations are lower, since beta-star test responses to all beta lactam antibiotics, including Penicillin G, whereas cylinder plate method just measures the levels of PG in milk samples. As it is demonstrated in Table 3, amongst raw milk samples Tehran showed the maximum contamination of $2.2 \mu \mathrm{g} . \mathrm{mL}^{-1}$, and Zanjan had the minimum average concentration of $0.5 \mu \mathrm{g} . \mathrm{mL}^{-1}$. Most of the milk samples did not have antibiotic contamination after pasteurization. This affair is only exceeded in Mashhad which showed an average concentration of $0.21 \mu \mathrm{g} \cdot \mathrm{mL}^{-1}$.

Results show the amount of contamination is dramatically reduced through the process of pasteurization. Beta-lactam ring within the structure of beta lactam antibiotics is highly heat-sensitive, and warming up the milk samples till $80{ }^{\circ} \mathrm{C}$ during the process of pasteurization causes this ring to be degraded. Since this ring plays a major role in the biological activities of beta lactam antibiotics, it would be suggested that pasteurization process removes antibiotic residues through degrading this ring. Since milk and dairy products are considered as a crucial part in nutrition pyramid, controlling the quality of the antibiotics would be an essential step before releasing those products in marketplaces. One of the major concerns in this field is monitoring the presence of antibiotic residues in milk, because the contamination is available in other dairy products as well. Among different antibiotics which are utilized as medicine to treat mastitis, Penicillin G is the most common one. In this study two types of experiments were performed to measure the amount of Penicillin $\mathrm{G}$ residues in milk. Results revealed that cylinder-plate method accompanied by beta-star test can be considered as an appropriate sensitive and selective method for the routine quality control of milk and dairy products.

\section{Acknowledgements}

The authors gratefully acknowledge the institute of standard and industrial research of Iran, Young Researches and Elites Club for its financial support of this study.

\section{Authors' Contribution}

None declared.

\section{Financial Disclosure}

None declared.

\section{Funding/Support}

None declared.

\section{References}

1. Samanidou V, Nisyriou S. Multi-residue methods for confirmatory determination of antibiotics in milk.JSep Sci. 2008;31(11):206890.

2. Piddock laura jV. Does the use of antimicrobial agents in veterinary medicine and animal husbandry select antibiotic-resistant bacteria that infect man and compromise antimicrobial chemotherapy? J Antimicrob Chemother. 1996;38(1):1-3.

3. Choma Irena, Grenda Dorota, Malinowska Irena, Suprynowicz Zdzisław. Determination of flumequine and doxycycline in milk by a simple thin-layer chromatographic method. J Chromatogr $B$ : Biomed Sci Appl.1999;734(1):7-14

4. Junza A, Amatya R, Barron D, Barbosa J. Comparative study of the LC-MS/MS and UPLC-MS/MS for the multi-residue analysis of quinolones, penicillins and cephalosporins in cow milk, and validation according to the regulation 2002/657/EC. JChromatogr B Analyt Technol Biomed Life Sci. 2011;879(25):2601-10.

5. Wang J, Leung D, Lenz SP. Determination of five macrolide antibiotic residues in raw milk using liquid chromatography-electrospray ionization tandem mass spectrometry. J Agric Food Chem. 2006;54(8):2873-80.

6. Specific and Nonspecific Sensitizing Agents. FAO/WHO Milk Hygiene. 1962.

7. Grove DC. Prevention of Antibiotics in Milk-Present Status. $J$ Dairy Sci. 1959;42(1):199-201. 
8. Brown RW. Residues in Milk from Antibiotics Used in Mastitis Treatment. The Nature and Pate of Chemicals Applied to Soils, Plants, and Animals Symposium. 1960. 189 pp.

9. Afnan M, Kashani M. [Study on the contamination of raw milk with antibiotics]. 1972.

10. Karim G, Navabpour C. Detection of antibiotic residues in raw milk. Iran J Pub Health. 1978;7(2):81.

11. Welch Henry, Jester William R, Burton JM. Antibiotics in fluid milk. Antibiotics Chemother. 1955;5(10):571.

12. Maicth EH, Ellickson BE. Antibiotic Residues in Milk and Milk Products-A Review. J Milk and Food Technol. 1959:22-241.

13. Dračková Michaela, Navrátilová Pavlína, Hadra Luboš, Vorlová Lenka, Hudcová Lenka. Determination Residues of Penicillin G and Cloxacillin in Raw Cow Milk Using Fourier Transform Near Infrared Spectroscopy. Acta Veterinaria Brno. 2009;78(4):685-690.

14. Martinez-Huelamo M, Jimenez-Gamez E, Hermo MP, Barron D, Barbosa J. Determination of penicillins in milk using LC-UV, LCMS and LC-MS/MS. J Sep Sci. 2009;32(14):2385-93.

15. Kress Claudia, Schneider Elisabeth, Usleber Ewald. Determination of penicillin and benzylpenicilloic acid in goat milk by enzyme immunoassays. Small Ruminant Res 2011;96(2):160-164.

16. Breier AR, Garcia CV, Oppe TP, Steppe M, Schapoval EES. Microbiological assay for azithromycin in pharmaceutical formulations.J Pharmaceut Biomed Analys. 2002;29(5):957-961.

17. Mohamadi Sani A, Nikpooyan H, Moshiri R. Aflatoxin M1 contamination and antibiotic residue in milk in Khorasan province, Iran. Food Chem Toxicol. 2010;48(8-9):2130-2.

18. The United States Pharmacopeia. Rockville; United States Pharmacopeial convention. 2000.

19. Commission of the European Communities, No. 2377/90 L224 1990.

20. ISO/CD 13969 Milk and Milk Products - Guidance for the Stan- dardized Description of Microbial Inhibitor Tests. International Organisation for Standardisation. 1998.

21. Heeschen WH, Suhren G. Proceedings of a Symposium on Residues of Antimicrobial Drugs and Other Inhibitors in Milk,. 1995.

22. Report of a survey of antibiotic test methods for raw milk, commissioned by the Dairy Industry Federation. Hannah Research Institute: Ayr. 1999.

23. WHO: Technical Report Series No. 430.1969.

24. Ramírez Acacia, Gutiérrez Rey, Díaz Gilberto, González Clementina, Pérez Norma, Vega Salvador, et al. High-performance thinlayer chromatography-bioautography for multiple antibiotic residues in cow's milk. J Chromatogr B. 2003;784(2):315-322.

25. Movassagh Mohammad Hosein, Karami Amir Reza. Determination of Antibiotic Residues in Bovine Milk in Tabriz, Iran. Global Veterinaria. 2010;5(3):195-7.

26. Kaya Seyda ERGIN, Filazi Ayhan. Determination of antibiotic residues in milk samples. Kafkas Univ Vet Fak Derg. 2010;16:S31-S35.

27. Khaskheli M, Malik RS, Arain MA, Soomro AH, Arain HH. Detection of ß-lactam antibiotic residues in market milk. Pak J Nutr. 2008;7(5):682-685.

28. Adesiyun AA, Webb LA, Balbirsingh V. Prevalence Of Antimicrobial Residues In Preprocessed And Processed Cows' Milk In Trinidad. J Food Safety. 1997;16(4):301-310.

29. Shitandi Anakalo, SternesjÖ ÅSe. Detection Of Antimicrobial Drug Residues In Kenyan Milk. JFood Safety. 2001;21(4):205-214.

30. Ceyhan I, Bozkurt M. Ankara piyasasdnda satdlan sütlerde penisilin araștdrmasd. Türk Hij Den Biyol Derg. 1987;44(1-5).

31. Present National Incidence of Antibiotic Residues in Milk. 88th Ann. Meet. American Public Health Association. San Francisco, Calif.; 1960 .

32. Johns CK. Substances in herd milks inhibiting acid production. Can. J. Agr. Sci.1953;33:586 